\title{
The activity-stress ulcer in the hamster
}

\author{
GEORGE P. VINCENT and WILLIAM P. PARE \\ VA Hospital, Perry Point, Maryland 21902
}

\begin{abstract}
Hamsters were fed for $11 / 2 \mathrm{~h}$ each day during the dark phase of an inverted day/night cycle and allowed access to an exercise wheel. At autopsy; all animals revealed lesions of the glandular stomach, while food-yoked control hamsters treated similarly, but not having an activity wheel, remained free of stomach pathology. Results indicate that this procedure is capable of reliably producing stomach lesions in this species if certain species-specific behaviors are first acknowledged.
\end{abstract}

Stomach lesions have been reliably produced in the laboratory rat by a number of experimental procedures (Ader, 1971). The extent to which such techniques are capable of producing stomach lesions in animal species other than the rat has been sparsely documented (Areari, Gaetani, Glasser, \& Turolla, 1968; Brodie \& Hanson, 1960; Pfeiffer, 1972). Vincent and Paré (1976) reported producing stomach lesions in four rodent species by employment of the “activity-stress"' procedure (Paré, 1974, 1975; Paré \& Houser, 1973). The results indicated that gastric lesions could be induced in the rat, hamster, gerbil, and guinea pig by housing them in individual activity cages and feeding them for $1 \mathrm{~h}$ each day. Although very few control animals (i.e., those not having an exercise wheel) revealed any stomach pathology, an unusually high proportion of hamster controls were found to have stomach lesions when autopsied. It was suspected at the time that inadequate food intake of both experimental and control animals may have partly contributed to the gastrointestinal pathology, thereby confounding the experimental outcome.

Kutscher (1969) has reported that the hamster is unable to adapt to a 2-h restricted feeding schedule. However, in the Kutscher report, as in our previous study, animals were fed during the light phase of the light-dark (L/D) cycle. Recently, Zucker and Stephans (1973) have shown that the hamster is primarily a nocturnal feeder. Therefore, when a restricted feeding schedule is used with this species, it would be appropriate to feed these animals during the night phase of the day-night $(\mathrm{D} / \mathrm{N})$ cycle in order to ensure that food intake will be at its maximum. The purpose of the present study was to repeat the "activity-stress" procedure, using the hamster to determine what manipulations were required to optimize the development of gastric lesions in this species.

Gratitude is expressed to K. Isom for technical assistance and to L. Gilliam of the Medical Illustration Service, VA Hospital, Perry Point, Maryland, for the photographic illustrations. The Veterans Administration Project Number is 641-6905-10.

\section{METHOD}

\section{Animals and Apparatus}

The animals comprised 20 male golden hamsters, 95-134 g, purchased from Haley Farms, Hunt, Virginia. The animals were housed individually in fabricated hardware wire cages measuring $30 \times 15 \times 21 \mathrm{~cm}$. The cages in which activity hamsters were housed contained a standard pet-shop exercise wheel which measured $54 \mathrm{~cm}$ in diameter $\times 7 \mathrm{~cm}$ wide. The exercise wheels were attached to the underside surface of the cages' wood covers. The control hamsters cages did not include an exercise wheel. All wheel revolutions were individually monitored for each activity cage by electromagnetic digital counters.

\section{Procedure}

The animals were divided equally into two weight-equivalent groups-an activity group and a food-yoked control group. Those designated as activity animals were individually placed in activity cages. Those assigned as food-yoked control animals were individually housed in cages not having activity wheels. All animals were maintained on a reversed L/D cycle for an 11-day habituation period for adaptation to new cage conditions and the L/D cycle inversion. During this period, all animals were given food and water ad lib. On Day 12, food was withdrawn from all activity animals. On Day 13 , food was withdrawn from food control hamsters. Activity animals were fed for $11 / 2 \mathrm{~h}$ between 9:00 and 10:30 a.m. on this and subsequent days. The amount of food consumed by activity hamsters was measured, and this amount was given to food controls on the next day. Therefore, food control animals were food-yoked to their experimental mates and lagged behind by $24 \mathrm{~h}$ for the duration of the study. Body weight and food consumption were recorded daily for all animals, as were the number of daily wheel revolutions for each activity animal. When an animal died, the stomach was removed and inspected for ulcers. The control mate was also sacrificed at the equivalent time and the stomach examined. The study was terminated with the death of the last activity animal.

\section{RESULTS}

All activity animals died between 4 and 13 days

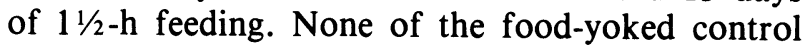
hamsters died during the study. Glandular stomach lesions, as shown in Figure 1, were evident in all activity animals, while food-yoked control animals were found to be free of stomach pathology. The ulcer data are summarized in Table 1.

Activity animals consumed a mean of $2.3 \mathrm{~g}$ during the $1 \frac{1}{2}-\mathrm{h}$ feeding periods. The mean percentage body 


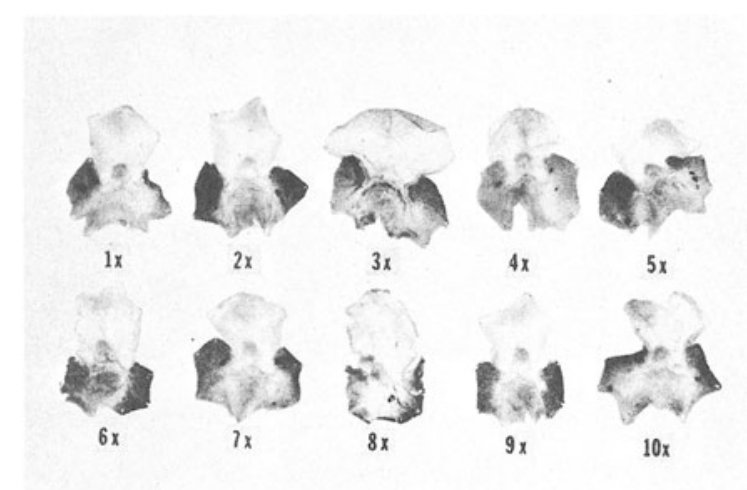

Figure 1. Ulcerated stomachs of the $\mathbf{1 0}$ experimental hamsters.

weight loss of the activity animals was compared to that of controls. Because fatalities were recorded after the 4th day of $11 / 2$-h feeding, only the first 4 days were used for statistical analysis. Activity animals showed a significantly greater body weight loss over these days as compared to controls $(\mathrm{F}=10.63, \mathrm{df}=2 / 18, \mathrm{p}<.01)$.

The activity pattern of the experimental hamsters was observed, and activity was found to reach a peak on Day 4 of $1 \frac{1}{2}-\mathrm{h}$ feeding. On Day 5 , peak activity decreased by more than $50 \%$, and for the duration of the study an elevation with minor fluctuations was seen but never again reached the level exhibited

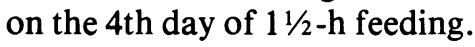

\section{DISCUSSION}

The results of this study indicated once again that gastric lesions may be induced in the hamster by the use of the "activity stress" procedure. Furthermore, the occurrence of lesions may be limited only to experimental animals and not control animals if certain adjustments are made. For the hamster, this requires that the animal be fed during the dark phase of the $\mathrm{D} / \mathrm{N}$ cycle in addition to increasing the restricted feeding period to $1 \frac{1}{2} \mathrm{~h}$. The latter adjust-

Table 1

Summary of Stomach Pathology for Experimental and Control Animals

\begin{tabular}{|c|c|c|c|c|c|}
\hline Group & $\mathbf{N}$ & Ulcers & $\begin{array}{l}\text { Mean } \\
\text { Ulcers/ } \\
\text { Hamster }\end{array}$ & $\begin{array}{c}\text { Mean } \\
\text { Length } \\
\text { (Milli- } \\
\text { meters) }\end{array}$ & $\begin{array}{c}\% \text { of } \\
\text { Stomach } \\
\text { Ulcer- } \\
\text { ated }\end{array}$ \\
\hline Experimental & 10 & 10 & 5.6 & 9.3 & 5.9 \\
\hline Control & 10 & 0 & 0 & 0 & 0 \\
\hline
\end{tabular}

ment was made to compensate for the intermittent feeding pattern that the hamster has been observed to exhibit even during the deprivation conditions (Kutscher, 1969).

There are, however, certain findings in this study that require some elaboration. The mean food intake of experimental hamsters during the restricted feeding periods was greater than that found in an earlier report (Vincent \& Paré, 1976) (i.e., from 0.63 to $2.3 \mathrm{~g}$ ). Also, an increase in the percentage of ulceration was observed (4.39 to 5.90) with a slight decrease in the mean number of ulcers resulting (7.5 to 5.6). In addition, the peak level in activity in this study was found to reach only slightly more than half the level observed in our first report. One possible explanation for this lower activity peak may be attributed to the extended habituation period which allowed the animals to habituate to the novelty of the activity wheel. Another hypothesis is the possibility that the lower consummatory patterns in the earlier study may have been instrumental in producing a higher drive state which was reflected by the higher daily running scores.

The present results have shown that careful consideration should be given to interspecies differences in behavior in order to effectively elicit an ulcerogenic event when using a new animal species.

\section{REFERENCES}

ADER, R. Experimentally induced gastric lesions. In H. Weiner (Ed.), Advances in psychosomatic medicine. Basel: S. Karger, 1971. Pp. 1-39.

Areari, G., Gaetani, M., Glasser, A. H., \& Turolla, E. Restraint-induced gastric ulcers in the golden hamster. Journal of Pharmacy and Pharmacology, 1968, 20, 73.

Brodie, D. A., \& Hanson, H. M. A study of the factors involved in the production of gastric ulcers by the restraint technique. Gastroenterology, 1960, 38, 353-360.

KUTSCHER, C. L. Species difference in the interaction of feeding and drinking. Annals of New York Academy of Sciences, 1969, 157, 539-552, Art. 2.

Paré, W. P. Feeding environment and the activity-stress ulcer. Bulletin of the Psychonomic Society, 1974, 4, 546-548.

PARÉ, W. P. The influence of food consumption and running activity on the activity-stress ulcer in the rat. American Journal of Digestive Diseases, 1975, 20, 262-273.

PARE, W. P., \& Houser, V. P. Activity and food-restriction effects on gastric glandular lesions in the rat: The activity-stress ulcer. Bulletin of the Psychonomic Society, 1973, 2, 213-214.

Pfeiffer, C. J. Peptic ulcer. Philadelphia: Lippincott, 1972.

Vincent, G. P., \& Paré, W. P. The activity-stress ulcer in the rat, hamster, gerbil and guinea pig. Physiology and Behavior, 1976, 16, 557-560.

ZuCKER, I., \& STEPhaNs, F. Light-dark rhythms in hamsters eating, drinking and locomotor behaviors. Physiology and Behavior, 1973, 11, 239-250.

(Received for publication August 16, 1976; revision accepted October $7,1976$. ) 